\title{
Preparation of nano phosphors by Microwave-assisted combustion synthesis
}

\author{
G. Sankar \\ GRD Centre for Materials Research, \\ PSG College of Technology, \\ Coimbatore Tamilnadu, \\ India
}

\author{
R. Arun Kumar \\ GRD Centre for Materials Research, \\ PSG College of Technology, \\ Coimbatore Tamilnadu, \\ India
}

\begin{abstract}
In this review article, we have discussed synthesizing of nano phosphor materials by the Microwave assisted Combustion process. Several literature conclude that efficient synthesis of nano phosphor materials can be achieved only through microwave-assisted combustion method. Also we have discussed about the principle and working process behind the Microwave process. After undergoing literature survey on combustion process we have discussed the preparation process of fuel to oxidizer ratio which plays a major role for obtaining nano powders that are essential in display application.
\end{abstract}

Key words: Microwave, Combustion process, Nano phosphors, Display application

\section{INTRODUCTION}

Nowadays, the interest of the scientific community has been devoted to the progress achieved in synthesis, structural characterization, and the physical properties of nanostructures. Due to their peculiar characteristic and size effects, nanocrystals often show some novel physical properties that are different from those of the bulk and that are of great interest both for fundamental studies and for potential technological applications 1-5]. Researchers have undertaken investigations of the influence of particle size on the optical and the electronic properties of nanocrystal materials containing rare-earth oxides $[6,7]$. Phosphors are a group of materials that show promising behaviour when synthesized in nano phase. Recently various phosphor materials have been actively investigated to improve their luminescent properties and to meet the development of different display and luminescence devices.

Phosphors are high purity inorganic materials that emit light when exposed to various radiations such as photons, electrons and electric field. The host crystal contains controlled levels of impurity ions (activators) which stimulate or enhance luminescence. Most inorganic compounds doped with rare earth ions form an important class of phosphors as they possess a few interesting characteristics such as excellent chemical stability, high luminescence efficiency, and flexible emission colors with different activators [8, 9]. Rare earth ions-activated nano structured materials have been attracting much interest in the past few years, due to the excellent luminescence and potential applications in luminescent devices and display equipment, such as lighting, field emission display (FED), cathode ray tubes (CRT), and plasma display panels (PDP) [10-15].

Phosphor materials can be prepare various method such as solid state reactions [16-17], co- precipitation methods [18-19], solgel methods [20-23] and spray pyrolysis process [24-
27] emulsion liquid membrane system, hydrothermal method, high energy ball milling method and combustion method. In general, the rare-earth doped phosphors are mainly synthesized by the solid-state reaction at high temperature. However, this method requires a high processing temperature, a long processing tim`e, repeated milling and washing with chemicals. These processes tend to degrade the luminescence property of the particles and yield irregularly shaped particles. Sol-gel method has also been employed to synthesize nanophosphors by many researchers. The as-prepared powders obtained from the sol-gel method have low crystallinity and often require post-treatment at high temperature, which results in severe agglomerations. Combustion synthesis is a promising particle preparation method because it can employ a wide range of precursors for synthesis of a broad spectrum of functional nanoparticles. The use of combustion can avoid hollowness and provide the high temperature environment which is favorable to phosphor synthesis. The flame temperature and particle residence time, which are very important parameters determining particle characteristics, can be easily controlled by varying fuel and oxidizer flow rates. Moreover, the particle size can be controlled by varying precursor solution concentration and multi-component particles can also be obtained by adding different salts into the solution.

Combustion synthesis offers many potential advantages over conventional technique of synthesis, including simple equipment, short processing time, lower energy requirement and higher purity. The initial combustion process used to the conventional furnace as heating system, However this heating method has some inconvenience such as consuming and generating non-homogenous product [28]. Recently a novel technique called 'microwave- assisted combustion synthesis' is used to synthesize oxide materials. 


\section{MICROWAVE SYNTHESIS:}

Microwave energy synthesis of various materials such as ceramics, metals and composites offers several advantages over conventional heating methods. These advantages include unique microstructure and properties, improved product yield, energy savings, reduction in manufacturing cost and synthesis of new materials.

Microwaves are electromagnetic waves with wavelengths from $1 \mathrm{~mm}$ to $1 \mathrm{~m}$ and corresponding frequencies between $300 \mathrm{MHz}$ and $300 \mathrm{GHz}$. [ $0.915 \mathrm{GHz}$ and 2.45 GHz] frequencies are commonly used for microwave heating. These frequencies are chosen for the microwave heating based on two reasons. The first is that they are in one of the industrial, scientific and medical (ISM) radio bands set aside for noncommunication purposes. The second is that the penetration depth of the microwaves is greater for these low frequencies. However, heating is not necessarily increased with decreasing frequency as the internal field (E) can be low depending on the properties of the material. $2.45 \mathrm{GHz}$ is mostly used for household microwave ovens and $0.915 \mathrm{GHz}$ is preferred for industrial/ commercial microwave ovens. Recently, microwave furnaces with variable frequencies from 0.9 to $18 \mathrm{GHz}$ have been developed for material processing (Sutton 1989; Thostenson and Chou 1999). Microwaves are coherent and polarized and can be transmitted, absorbed, or reflected depending on the material type [29].

Microwave energy is delivered directly to the material through molecular interaction with the electromagnetic field. Microwave heating is the transfer of electromagnetic energy to thermal energy and is energy conversion rather than heat transfer. Since microwaves can penetrate the material and supply energy, heat can be generated throughout the volume of the material resulting in volumetric heating. Hence, it is possible to achieve rapid and uniform heating of thick materials. Therefore, the thermal gradient in the microwave processed material is the reverse of that in the material processed by conventional heating. In conventional heating, slow heating rates are selected to reduce steep thermal gradient leading to process-induced stresses. Thus, there is a balance between processing time and product quality. During microwave processing, the potential exists to reduce processing time and enhance product quality as microwaves can transfer energy throughout the whole volume of the material. In this case, energy transfer occurs at a molecular level that can have some additional advantages. When microwave energy is in contact with materials having different dielectric properties, it will selectively couple with the higher loss tangent material. Therefore, microwaves can be used for the selective heating of the materials. Figure 1 shows a schematic diagram of a typical microwave oven.

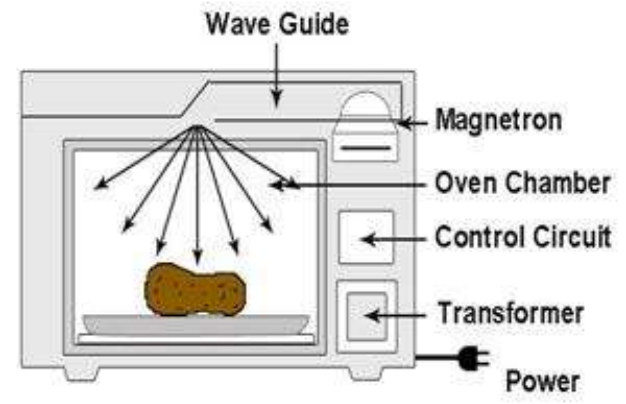

Figure 1 shows schematic diagram of a typical microwave oven.

\subsection{Microwave-material interaction}

Microwave energy is transferred to the material by interaction of the electromagnetic field at the molecular level. The dielectric properties determine the effect of the electromagnetic field on the material. The interaction of microwaves with a dielectric material results in translational motions of free or bound charges and rotation of the dipoles. The resistance of these induced motions due to inertial, elastic, and frictional forces causes losses resulting in volumetric heating

The power absorbed per unit volume, $\mathrm{P}\left(\mathrm{W} / \mathrm{m}^{3}\right)$ is expressed as (Sutton 1989),

$$
P=\sigma|E|^{2}=2 \pi f \varepsilon_{0} \varepsilon_{r}^{\prime} \tan \delta|E|^{2},
$$

Where $\mathrm{E}(\mathrm{V} / \mathrm{m})$ is the magnitude of the internal field, $\sigma$ the total effective conductivity $(\mathrm{S} / \mathrm{m}), \mathrm{f}$ the frequency $(\mathrm{GHz})$, $\varepsilon_{0}$ the permittivity of free space $\left(\varepsilon_{0}=8.86 \times 10-12 \mathrm{~F} / \mathrm{m}\right), \varepsilon_{\mathrm{r}}^{\prime}$ the relative dielectric constant and $\tan \delta$ the loss tangent. Equation (1) demonstrates that the power absorbed varies linearly with the frequency, the relative dielectric constant, loss tangent and the square of the electric field. The penetration depth of the microwaves (D) at which the incident power is reduced by one half is expressed as

$$
\mathrm{D}=\frac{3 \lambda_{0}}{8.686 \pi \tan \delta\left(\varepsilon_{\mathrm{r}}^{\prime} / \varepsilon_{0}\right)^{1 / 2}}
$$

where $\lambda_{0}$ is the incident or free-space wavelength The relative dielectric constant and the loss tangent are the parameters that describe the behavior of a dielectric material under the influence of the microwave field. [30].

Microwave synthesis can be used to produce various materials such as, ceramic powders, nanotubes, glasses, micro tubes, metal powder and nanomaterials. Microwave assisted combustion synthesis is one of the approach to produce nano phosphor material. 


\section{MICROWAVE ASSISTED COMBUSTION SYNTHESIS}

Solution combustion is a well-known method for rapid synthesis of rare earth activated insulating materials at low temperatures $\left(350-500^{\circ} \mathrm{C}\right)$ and very short times $(<5$ minutes). Although oxide phosphors synthesized by a combustion reaction have lowvoltage cathodoluminescence efficiencies, hydrothermal, solidstate and combustion methods yield the same efficiencies at excitation voltages below $600 \mathrm{~V}$. Different structures of tricolor phosphors such as oxides, vanadates, borates, aluminates, etc., can be synthesized using a solution combustion method[31].

For the preparation of $\mathrm{GdCaAl}_{3} \mathrm{O}_{7}$ : Eu nanoparticles[32], All the chemicals used were of high purity (Aldrich 99.99\%). Stoichiometric amounts of metal nitrates $\mathrm{Ca}\left(\mathrm{NO}_{3}\right)_{2} \cdot 4 \mathrm{H}_{2} \mathrm{O}$, $\mathrm{Al}\left(\mathrm{NO}_{3}\right)_{3} \cdot 9 \mathrm{H}_{2} \mathrm{O}, \mathrm{Eu}\left(\mathrm{NO}_{3}\right)_{3}$ and $\mathrm{Gd}\left(\mathrm{NO}_{3}\right)_{3}$ were mixed in minimum doubly distilled water. Then the fuel to oxidizer $(\mathrm{F} / \mathrm{O})$ ratio was calculated based on the following Stoichiometric equation.

$0.95 \mathrm{Gd}(\mathrm{NO} 3) 3+0.05 \mathrm{Eu}(\mathrm{NO} 3) 3+\mathrm{Ca}(\mathrm{NO} 3) 2+$

$3 \mathrm{Al}(\mathrm{NO} 3) 3+8 \mathrm{NH} 2 \mathrm{CH} 2 \mathrm{COOH}+0.5 \mathrm{O} 2 \rightarrow$

Gd0.95CaAl3O $7: \mathrm{Eu} 0.05+16 \mathrm{CO} 2+20 \mathrm{H} 2 \mathrm{O}+11 \mathrm{~N} 2$

The fuel to oxidizer ratio determined by following formula

$\Phi_{\mathrm{e}}=\frac{\sum(\text { coeff } . \text { of oxidizing element in specific formula }) \times(\text { valancy })}{-1 \sum(\text { coeff. of reducing element in specific formula }) \times(\text { valency })}$

Stoichiometric proportions of the reactants yield $\Phi_{\mathrm{e}}=1$, fuellean proportions yield $\Phi_{\mathrm{e}}>1$, and fuel-rich proportions yield $\Phi_{\mathrm{e}}$ $<1$ [33]. Then, Stoichiometric amounts of fuel (such as urea, Glysine, hydra zinc, (carbohydrazide) were added. The final solution was converted to a gel by heating up to $80-90{ }^{\circ} \mathrm{C}$. The beaker was transferred into a microwave oven (Samsung, Korea, $900 \mathrm{~W}, 2.45 \mathrm{GHz}$ frequency) to complete the combustion reaction. All experiments were performed at a maximum power of microwave for 50 seconds.

The structures of the powders obtained were characterized by X-ray Diffraction (XRD). The morphology of the particles and agglomerates ere also investigated by a scanning electron microscope (SEM) and a transmission electron microscope (TEM). The luminescent properties of the powders obtained were characterized using a photoluminescence spectrophotometer. This technique has been applied to successfully synthesize a variety of oxide phosphors, such as $\mathrm{GdCaAl}_{3} \mathrm{O}_{7}$ : $\operatorname{Tr}$ [34], $\mathrm{Y}_{2}-\mathrm{xO}_{3}: \mathrm{xTb}^{3+}$ [35], these nano phosphors are used to red, green, and blue color emission in plasma display panels.
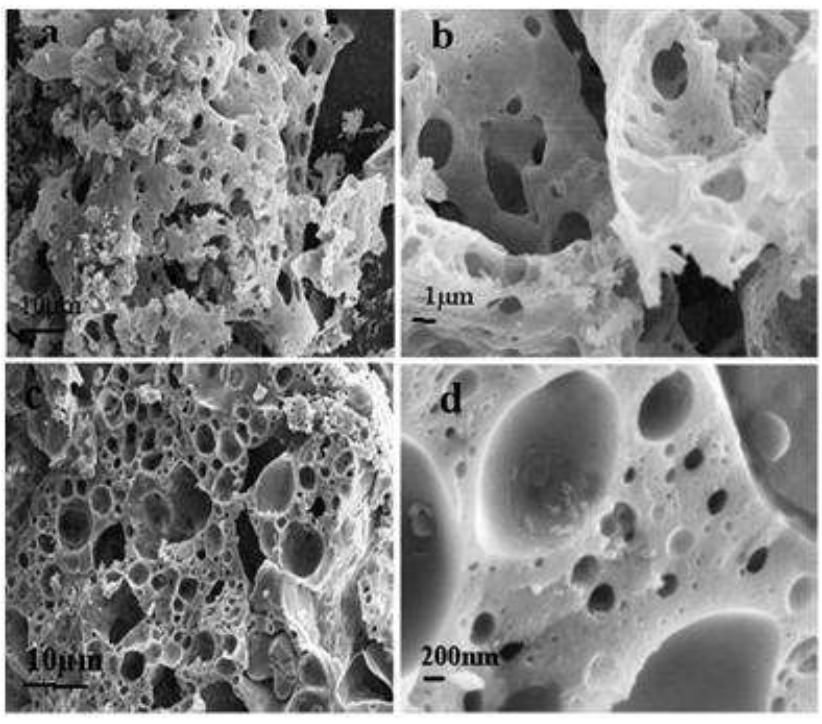

Figure.2 SEM images of $\mathrm{GdCaAl}_{3} \mathrm{O}_{7}: \mathrm{Eu}(\operatorname{Ref} 32)$

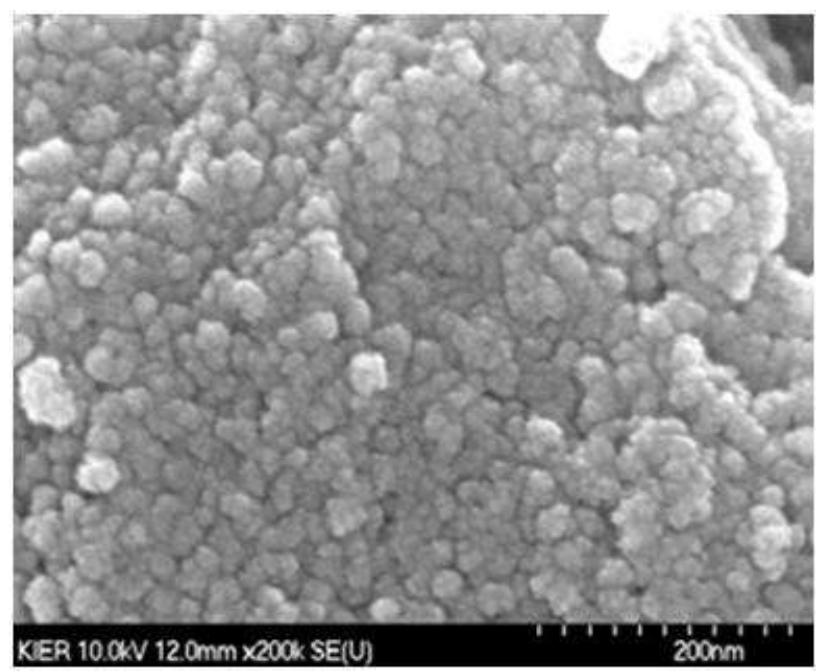

Figure.3 SEM images of $\mathrm{GdCaAl}_{3} \mathrm{O}_{7}: \mathrm{Tb}^{3+}(\operatorname{Ref} 34)$

\section{CONCLUSION}

In the past few decades significant developments in the field of microwave assisted combustion process for the preparation of nano phosphor materials have taken place vigorously. In accordance with this process many research works are being conducted to obtain a detailed understanding about the nature and distribution of the electromagnetic field inside the microwave cavity, microwave-material interaction, material transformations and heat transfer mechanisms for optimizing the process. Thus Microwave-assisted combustion synthesis is suitable method for the preparation of nano phosphor materials, since it is a short time process. 


\section{REFERENCES}

[1] Yoffe, D. A., Adv.Phys. 42, 173 (1993).

[2] Bhargava, N.R., and Gallagher D., Phys. Rev. Lett. 72, 416 (1994).

[3] Luo, L.J., Ying, T.X., Wang N.P., and Chen, Y.L., J., Korean Phys. Soc. 46, S224 (2005).

[4] Creekmore, S., Seo, T.J., Yang, Q., Wang Q., Anderson J., Pompey C., D., Temple, X., Peng, J. L., Qu, W. Yu, A. Wang J., Mott, A., Namkung M, Jung S.S., and Kim H.J., Korean Phys. Soc. 42, S143 (2003).

[5] Hwang, S.K., Jeon, S.Y., Kang A.B., Nishio K, T., Tsuchiya T., An H.J., and Kim H B, J., Korean Phys. Soc. 46, 521 (2005).

[6] Jia, Y.W., Wang, Y.Y., and Fernandez F., Mater. Sci. Eng. C 16, 55 (2001).

[7] Kenyonn, J.A., Chryssou E.C., and Pitt W.C., J. Appl. Phys. 91, 367 (2002).

[8] Wang H. Y., Wang Y. Z., Zhang Y. P., Z. L., Hong, Fan P. X., Mater. Lett. 2004, 58: 3308.

[9] Feldmann, C., Jüstel T., Ronda R. C., Schmidt J. P., Adv. Funct. Mater 2003, 13, 511.

[10] Kenyonn J. A., Chryssou E. C., and Pitt W. C., J. Appl. Phys., 2002, 91, 367.

[11] Li H.Y., and Hong Y.G., J. Solid State Chem., 2005 , $178,645$.

[12] Dhanaraj, J., Jagannathan, R., Kutty N.R.T., and Lu, C.H., J. Phys. Chem., 2001, B 105,11098.

[13] Wei G.Z., Sun D.L., Liao S.C., Yan H.C., and. Huang, S.H., Appl. Phys. Lett., 2002, 80,1447.

[14] Khatkar P.S., Han D.S., Taxak B.V., Kumar, D., and Kumar, R., J. Lumin., 2007, 126, 597.

[15] Sohn S.K., Zeon W., Chang H., Lee K. S., and Park, D. H., Chem. Mater., 2002, 14, 2140.

[16] Issler, L. S., and Torardi C. C., J. Alloy Compd. 229, $54,1995$.

[17] Neeraj, S., Kijima, N., and Cheetham K. A., Solid State Commun. 131, 65, 2004.

[18] He, C., Guan, Y., Yao, L., Cai, W. X., Li and Yao, Z., Mater. Res. Bull. 38, 973, 2003.

[19] Ko G M, J.C. Park, D. Kuk and S. H. Byeon, J. Lumin. 104, 215, 2003.

[20] Zhang, J., ZTang, Z., Zhang, Z., Fu, W., Wang, J. and Lin, Y., Mater. Sci. Eng. A, 334, 246, 2002.

[21] Ruan, K. S., Zhou, G. J., A Zhong M .A., Duan F. J., Yang, B. X., and Su, Z. M. J., Alloy Compd. 275, 72, 2003.

[22] Park, J. C., Moon, H. K.. Kim, D. K., Byeon, S. H., Kim B. C., .and. Suh, K. S., Appl. Phys. Lett. 77, 2162, 2000.

[23] Yan, B., and Zhou L., J. Alloy Compd. 372, 238, 2004.

[24] Kang C. Y., Park, B. S., , Lenggoro, W. L., and Okuyama K., J. Phys. Chem. Solids. 60, 379, 1999.

[25] Kang, C .Y., Lenggoro ,W. L., Park, B. S., and Okuyama K., J. Phys. Chem. Solids. 60, 1855, 1999.

[26] Kang, C. Y., Roh, S. H., Park, S. B., and Park, D. H., J. Eur. Ceram. Soc. 22, 1661, 2002.
[27] Roh, S. H., Kang, C. Y., and Park, B. S., J. Colloid Interf.Sci. 228, 195, 2000.

[28] Sousan Rasoulia, Amir M. Arabib and Saeideh Gorji Kandic, Journal of Ceramic Processing Research. Vol.13,No. 1, pp. 47 51 (2012)

[29] Clark, D., and Sutton, W. H., 1996 Annu. Rev. Mater. Sci. 26299

[30] Das, S., Mukhopadhyay, K. A., Datta, S., and Basu, D., Bull. Mater. Sci., Vol. 32, No. 1, February 2009, pp. 1-13. () Indian Academy of Sciences.

[31] Ekambaram, S., Patilb K.C., and Maazac, M. J. Alloy. Compd.393 (2005) 81-92

[32] Sousan Rasoulia, Amir, M., Arabib and Saeideh Gorji Kandic, Journal of Ceramic Processing Research. Vol13, No. 1, pp. 47 51 (2012)

[33] Jain, R. S., Adiga, C. K., and Paiverneker, R. V., "A new approach to thermochemical calculations of condensed fuel-oxidizer mixtures," Combustion and Flame 40, 71-79 (1981).

[34] Taxak, B. Dinesh Kumara, V., Khatkara Sang Do Hanb, S.P., 211th ECS Meeting, Abstract \#1175,

[35] Devender Singh et al Arch. Appl. Sci. Res., 2012, 4 (1):518-523 